\title{
Stathmin 1 expression is associated with aggressive phenotypes and cancer stem cell marker expression in breast cancer patients
}

\author{
SAYAKA OBAYASHI ${ }^{1}$, JUN HORIGUCHI $^{2}$, TORU HIGUCHI $^{3}$, AYAKA KATAYAMA $^{4}$, TADASHI HANDA ${ }^{4}$, \\ BOLAG ALTAN $^{5}$, TUYA BAI ${ }^{5}$, PINJIE BAO ${ }^{5}$, HALIN BAO $^{5}$, TAKEHIKO YOKOBORI ${ }^{6}$, \\ MASAHIKO NISHIYAMA ${ }^{7}$, TETSUNARI OYAMA ${ }^{4}$ and HIROYUKI KUWANO ${ }^{5,8}$ \\ ${ }^{1}$ Division of Breast and Endocrine Surgery, Integrative Center of General Surgery, Gunma University Hospital, \\ Maebashi, Gunma; ${ }^{2}$ Department of Breast Surgery, Graduate School of Medical Sciences International University \\ of Health and Welfare, Gunma; ${ }^{3}$ Breast Surgery Unit, Japanese Red Cross Saitama Hospital, Saitama; Departments of \\ ${ }^{4}$ Diagnostic Pathology, and ${ }^{5}$ General Surgical Science, Gunma University Graduate School of Medicine, Gunma; ${ }^{6}$ Research \\ Program for Omics-based Medical Science, Division of Integrated Oncology Research, Gunma University Initiative \\ for Advanced Research, Gunma; ${ }^{7}$ Department of Molecular Pharmacology and Oncology, Gunma University Graduate \\ School of Medicine, Gunma; ${ }^{8}$ Integrative Center of General Surgery, Gunma University Hospital, Gunma, Japan
}

Received February 14, 2017; Accepted June 26, 2017

DOI: $10.3892 /$ ijo.2017.4085

\begin{abstract}
Stathmin1 (STMN1) regulates progression in various cancers. The present study aimed to determine the relationship between STMN1 expression and several cancer-related markers in breast cancer. Using immunohistochemistry, we evaluated STMN1, estrogen receptor, progesterone receptor, human epidermal growth factor receptor 2, Ki-67, epidermal growth factor receptor (EGFR), CK5/6, CD44, CD24, aldehyde dehydrogenase 1, E-cadherin, epithelial cell adhesion molecule, and vimentin in 237 breast cancer patients and the clinical significance of STMN1. STMN1 expression was evaluated in 51 breast cancer cell lines, and the prognostic value of STMN1 was calculated. Higher STMN1 expression was detected in cancer tissues and was predominantly localized in the cyto-
\end{abstract}

Correspondence to: Dr Takehiko Yokobori, Research Program for Omics-based Medical Science, Division of Integrated Oncology Research, Gunma University Initiative for Advanced Research, 3-39-22 Showamachi, Maebashi 371-8511 Japan

E-mail: bori45@gunma-u.ac.jp

Abbreviations ER, estrogen receptor; PgR, progesterone receptor; HER2, human epidermal growth factor receptor 2; IHC, immunohistochemistry; EGFR, epidermal growth factor receptor; ALDH1, aldehyde dehydrogenase 1; STMN1, stathmin1; GOBO, gene expression-based outcome for breast cancer online; KM, Kaplan-Meier; BCSCs, breast cancer stem cells; TMA, tissue microarray; TNBC, triple-negative breast cancer; CSC, cancer stem cells; LI, labeling index; EMT, epithelial-to-mesenchymal transition; FFPE, formalin-fixed paraffin-embedded; RFS, recurrence-free survival; OS, overall survival; CI, confidence interval; HR; hazard ratio

Keywords: STMN1, triple-negative breast cancer, therapeutic target, tubulin destabilization, OP18 plasm. High STMN1 expression was associated with the triple negative subtype, nuclear grade progression, high expression of Ki-67, EGFR, CK5/6, E-cadherin and high CD44/low CD24. According to gene expression-based outcome for breast cancer online and the Kaplan-Meier plotter, STMN1 expression was higher in basal-type cell lines than in luminal-type cell lines, and overall survival and post-progression survival in the high STMN1 expression breast cancer patients were shorter than in low STMN1 expression patients. High STMN1 expression is a possible marker of breast cancer aggressiveness in association with proliferation, phenotype and cancer stem cell type.

\section{Introduction}

Breast cancer is the most frequently diagnosed cancer and is the leading cause of cancer death among females worldwide, with an estimated 1.7 million cases and 521,900 deaths in 2012 (1). Breast cancer alone accounts for $25 \%$ of all cancer cases and $15 \%$ of all cancer deaths among females. If diagnosed at an early stage, breast cancer patients often completely recover. However, many cases recur and develop gradual therapeutic resistance. To improve the prognosis of breast cancer patients, further research is required worldwide to identify new therapeutic targets.

Stathmin1 (STMN1), also known as oncoprotein 18, is a cytosolic phosphoprotein and a key regulator of cell division due to its microtubule depolymerization in a phosphorylation-dependent manner (2-4). STMN1 interacts with and sequesters free tubulin leading to microtubule depolymerization in vitro (5). STMN1 expression is associated with breast cancer proliferation $(6,7)$. STMN1 overexpression correlates with low estrogen receptor (ER) expression, low progesterone receptor $(\mathrm{PgR})$ expression and high histological grade in human primary breast cancer (6).

Since Perou et al (8) and Sørlie et al (9) performed breast cancer gene expression profiling using cDNA microarray in 
2000, intrinsic subtype classification based on gene expression profiling has been attracting attention. According to this classification, an alternative subtype classification based on the immunohistochemical analysis of $\mathrm{ER}, \mathrm{PgR}$, human epidermal growth factor receptor 2 (HER2) and Ki-67, mainly obtained by common pathological examination, is used for the clinical strategy (10). Triple-negative breast cancers (TNBCs) characterized by the absence of ER, PgR and HER2 expression have relatively poor outcomes and often exhibit treatment resistance (11). TNBCs are not eligible for endocrine therapies or anti-HER2-targeted therapies; this represents a substantial problem as there is no clear treatment target.

TNBCs are associated with cancer stem cells (CSCs) in breast cancer $(12,13)$. CSCs are a small cell population with unique characteristics such as self-renewal and multipotency. The high CD44/low CD24 breast cancer cell phenotype is associated with a subpopulation of tumorigenic stem cells (14). Breast cancer cells with increased aldehyde dehydrogenase 1 (ALDH1) activity have stem cell properties (15). Breast cancer stem cells (BCSCs) are associated with therapeutic resistance as well as growth, diversity and metastasis of breast cancer $(16,17)$. Therefore, it is hoped that BCSCtargeted therapies will be developed to overcome therapeutic resistance. Epithelial-to-mesenchymal transition (EMT) also has an important role in cancer progression and metastasis. Through EMT, cancer cells invade the vascular system and metastasize $(18,19)$. The relationships between CSCs and EMT are still controversial.

High STMN1 expression is associated with poor prognosis in breast cancer patients (20-22). Furthermore, taxane sensitivity is low in breast cancer cell lines with STMN1 overexpression (23). However, few studies have addressed the relationship between STMN1 and CSCs and EMT, which are attracting attention as a treatment target in breast cancer, in particular TNBCs.

The present study aimed to determine the clinical significance of STMN1 and its association with the expression of CSC markers, EMT markers and several cancer-related markers in breast cancer. Therefore, we retrospectively investigated the expression of STMN1 and CSC markers, including CD44/CD24 and ALDH1, in breast cancer tissue samples using immunohistochemistry to evaluate whether STMN1 qualifies as a marker of cancer progression and cancer stem cell type in breast cancer patients. Furthermore, we evaluated the expression of E-cadherin and epithelial cell adhesion molecule (EpCAM) as representative epithelial markers and the expression of vimentin as a representative mesenchymal marker to determine the association between STMN1 expression and EMT.

\section{Materials and methods}

Patients. We retrospectively analyzed tumor specimens from 237 patients with primary breastcancer who underwent primary tumor excision between January 1999 and October 2010 (180 patients were randomly selected from patients who underwent surgery between January 1999 and December 2002, and all patients with TNBC subtype who underwent surgery between January 2008 and December 2010 were included) at Breast and Endocrine Surgery of Gunma University Hospital. The inclusion criteria were as follows: histologically proven diagnosis of primary breast cancer; potentially curative operation was performed; and complete pathological records. The exclusion criteria were as follows: breast cancer with synchronous multiple cancers; stage IV cancer in preoperative diagnosis; and lost to the pathological records. The patients included 1 man and 236 women with a median age at surgery of 55 years (range, 28-95 years). Eighty patients had stage I, 101 had stage II and 50 had stage III breast cancer at the time of the surgery. In addition, 137 (57.8\%) patients were negative and $95(40.1 \%)$ patients were positive for lymph node metastasis, and $132(55.7 \%)$ patients were ER positive, 99 (41.8\%) patients were $\mathrm{PgR}$ positive, and 47 (19.8\%) patients had 2+ or $3+$ HER2 scores.

Tumor staging was based on the Union for International Cancer Control TNM classification, seventh edition (24). The nuclear grades were defined as the sum of scores for nuclear atypia (1, low-degree atypia; 2, intermediate-degree atypia; 3 , high-degree atypia) and mitotic count per 10 high-power fields (x40 objective lens; 1, 0-4 mitoses; 2, 5-10 mitoses, 3 , $\geq 11$ mitoses). The nuclear grade was 1,2 and 3 when the sum of scores for nuclear atypia and mitotic counts were 2-3, 4 and $5-6$, respectively (25). This study was in accordance with the Declaration of Helsinki. The Ethics Committee of Gunma University approved the study protocol.

Tissue microarray (TMA). Clinical formalin-fixed paraffinembedded (FFPE) samples were stored in the archives of the Clinical Department of Pathology, Gunma University Hospital. For each patient, one paraffin block containing representative non-necrotic tumor areas was selected. Breast cancer tissue cores (2.0-mm diameter per tumor) were punched out from the representative areas near the invasive front and transferred into the paired recipient paraffin block using a tissue array instrument (Beecher Instruments, Silver Spring, MD, USA).

Immunohistochemistry (IHC). A 4- $\mu \mathrm{m}$ section was cut from the sample paraffin blocks. Each section was mounted on a silane-coated glass slide, deparaffinized, and soaked for $30 \mathrm{~min}$ at room temperature in $0.3 \% \mathrm{H}_{2} \mathrm{O}_{2}$ /methanol to block endogenous peroxidases. The sections were then heated in boiling water and Immunosaver (Nishin EM, Co., Ltd., Tokyo, Japan) at $98^{\circ} \mathrm{C}$ for $45 \mathrm{~min}$. Non-specific binding sites were blocked by incubating with Protein Block serum-free (Dako, Carpinteria, CA, USA) for $30 \mathrm{~min}$. A mouse monoclonal antiSTMN1 (OP18) antibody (Santa Cruz Biotechnology, Santa Cruz, CA, USA) was applied at a dilution of 1:100 for $24 \mathrm{~h}$ at $4^{\circ} \mathrm{C}$. The primary antibody was visualized using the Histofine Simple Stain PO (M) kit (Nichirei, Tokyo, Japan), according to the instructions manual. Chromogen 3,3'-diaminobenzidine tetrahydrochloride was applied as a $0.02 \%$ solution containing $0.005 \% \mathrm{H}_{2} \mathrm{O}_{2}$ in $50 \mathrm{mM}$ ammonium acetate-citrate acid buffer (pH 6.0). The sections were lightly counterstained with Mayer's hematoxylin and mounted. Negative controls were established by omitting the primary antibody.

Other IHC was performed using the following primary antibodies: anti-ER (SP1; Ventana Medical Systems, Inc., Tucson, AZ, USA), anti-PgR (1E2; Ventana Medical Systems), anti-HER2 (4B5; Ventana Medical Systems), anti-Ki-67 (30-9; Ventana Medical Systems), anti-epidermal growth 

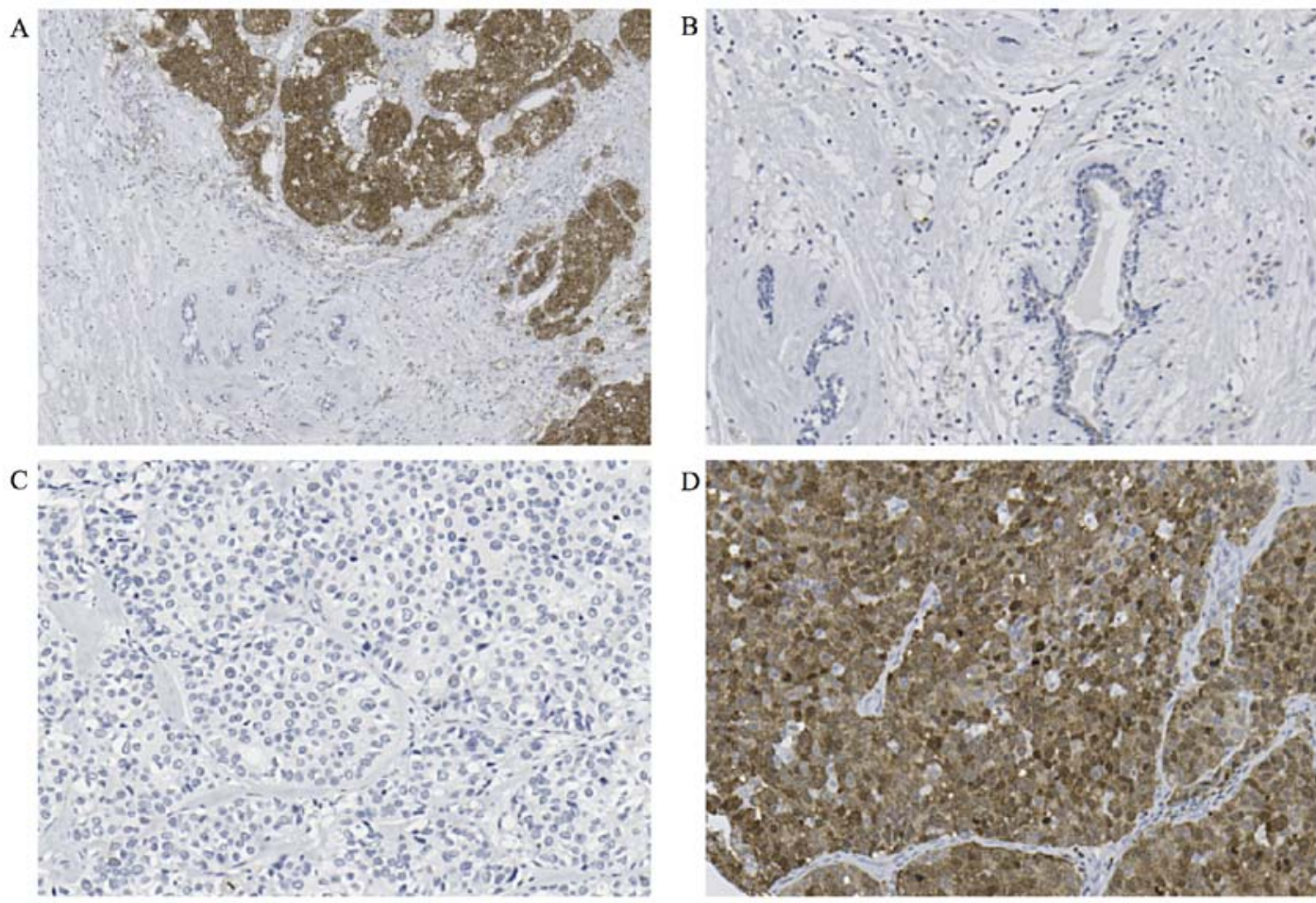

Figure 1. Immunohistochemical analysis of STMN1 expression in a representative breast cancer tissue and normal tissue samples. (A) High STMN1 expression in the breast cancer tissue (upper right corner of the figure) and low STMN1 expression in the normal adjacent breast tissue (lower left corner of the figure) (magnification, x100). (B) Low STMN1 expression in the normal breast tissue (magnification, x200). (C) Low STMN1 expression in the breast cancer tissue (magnification, x200). (D) High STMN1 expression in the breast cancer tissue (magnification, $\mathrm{x} 200$ ).

factor receptor (EGFR) (31G7; Nichirei), anti-cytokeratin 5/6 (CK5/6) (D5/16;B4; Dako, Glostrup, Demark), anti-E-cadherin (36; Ventana Medical Systems), anti-ALDH1 (46/ALDH; BD Biosciences, Franklin Lakes, NJ, USA), anti-CD44 (DF1485; Dako), anti-CD24 (SN3b; Thermo Fisher Scientific, Fremont, CA, USA), anti-EpCAM (D9S3P; Cell Signaling Technology, Inc., Danvers, MA, USA) and anti-vimentin (M725; Dako).

Immunohistochemical evaluation and subtype classification. The cut-off value for ER and PgR positivity was $1 \%$. HER2 expression was scored according to the American Society of Clinical Oncology/College of American Pathologists guidelines $(0$, no reactivity or membranous reactivity in $<10 \%$ of cells; $1+$, faint/barely perceptible membranous reactivity in at least $10 \%$ of cells or reactivity in only part of the cell membrane; $2+$, weak to moderate complete membranous reactivity in at least $10 \%$ of tumor cells; $3+$, strong complete membranous reactivity in at least $10 \%$ of tumor cells) (26). The Ki-67 labeling index (LI) was used to calculate the percentage of cells with high nuclear expression in $~ 1000$ cells/sample (27). The Ki-67 LI assumes a 14\% cut-off value (28). EGFR, CD44 and EpCAM expression were scored in the same way as HER2 expression; 0 and $1+$ scores were considered to be negative, and $2+$ and $3+$ scores were considered to be positive. The cut-off values for CK5/6, E-cadherin and ALDH1 used $10 \%$. If there was even a slightly stained positive part, the expression of CD24 and vimentin was considered to be positive.

When the cytoplasm of the cells was stained, the cells were STMN1-expression positive. In addition, for each case, we determined a modified Allred score, which is a semiquantitative system that takes the proportion of positive cells into consideration $(0$, none; $1,0-1 \% ; 2,1-10 \% ; 3,10-33 \% ; 4$, $33-66 \%$; and 5, 66-100\%) and staining intensity (0, none; 1 , weak; 2, intermediate; and 3, strong) (29). The proportion score and the intensity score were then summed to produce total scores of 0 or 2 through 8 . A score of 0-3 was defined as low STMN1 expression and a score of 4-8 was defined as high STMN1 expression.

Based on IHC, we defined the breast cancer subtypes as follows: luminal A-like (ER ${ }^{+}$, HER2 $0 / 1^{+}$and Ki-67 low), luminal B-like (ER ${ }^{+}$, HER2 $0 / 1^{+}$and Ki-67 high), luminalHER2 $\left(\mathrm{ER}^{+}\right.$and HER2 $\left.2^{+} / 3^{+}\right)$, HER2 $\left(\mathrm{ER}^{-}\right.$and HER2 $\left.2^{+} / 3^{+}\right)$, and triple negative (ER ${ }^{-}$and HER2 $0 / 1^{+}$).

Data mining. We used the gene expression-based outcome for breast cancer online (GOBO) to obtain information on STMN1 expression in 51 breast cancer cell lines (30). GOBO is an online tool that enables assessment of gene expression levels in breast cancer specimens and breast cancer cell lines.

We also used an online database Kaplan-Meier (KM) plotter to validate the association between STMN1 mRNA expression and overall survival (OS) and post-progression survival in breast cancer patients (31). The KM plotter is an entirely independent patient database with large-scale survival data, which can be stratified by selected genes and characteristics, such as histology, stage and sex.

Statistical analysis. Statistical analysis was performed using the t-test for continuous variables and the Chi-square test for categorical variables. Survival curves were generated according to the Kaplan-Meier method. Differences between survival curves were examined using the log-rank test. A 
Table I. Correlation between the expression of STMN1 and the clinicopathological characteristics of breast cancer patients.

\begin{tabular}{|c|c|c|c|c|c|c|c|}
\hline & & & & & & & \\
\hline & & & & & STMN1 & pression & \\
\hline & STMN1 e & xpression & & & & High & \\
\hline Chorocterictics & $\begin{array}{c}\text { Low } \\
\text { expression }\end{array}$ & $\begin{array}{l}\text { High } \\
\text { expression }\end{array}$ & P & Characteristics & $\begin{array}{c}\text { expression } \\
(\mathrm{n}=171)\end{array}$ & $\begin{array}{l}\text { expression } \\
\quad(n=66)\end{array}$ & P-value \\
\hline & & & & EGFR & & & $0.034^{\mathrm{a}}$ \\
\hline Age (years), mean $\pm \mathrm{SE}$ & $56.6 \pm 12.11$ & $53.8 \pm 13.29$ & 0.121 & Negative & 160 & 56 & \\
\hline Tumor size $(\mathrm{cm})$, & $2.3 \pm 1.51$ & $2.6 \pm 2.43$ & 0.233 & Positive & 11 & 10 & \\
\hline mean $\pm \mathrm{SE}$ & & & & CK5/6 & & & $0.001^{\mathrm{a}}$ \\
\hline Stage & & & 0.7 & Negative & 168 & 58 & \\
\hline 0 & 3 & 0 & & Positive & 3 & 8 & \\
\hline I & 57 & 23 & & Basal-like type $^{\mathrm{b}}$ & & & $<0.001^{\mathrm{a}}$ \\
\hline II & 71 & 30 & & Basal & 7 & 12 & \\
\hline III & 37 & 13 & & Non-basal & 164 & 54 & \\
\hline Unknown & 3 & 0 & & ALDH1 & & & 0.102 \\
\hline Lymph node metastasis & & & 0.192 & Negative & 161 & 58 & \\
\hline Negative & 103 & 34 & & Positive & 10 & 8 & \\
\hline Positive & 64 & 31 & & CD44 & & & $<0.001^{\mathrm{a}}$ \\
\hline Unknown & 4 & 1 & & Negative & 143 & 34 & \\
\hline Lymphatic invasion & & & 0.557 & Positive & 27 & 32 & \\
\hline Negative & 56 & 19 & & Unknown & 1 & 0 & \\
\hline Positive & 115 & 47 & & $\mathrm{CD} 24$ & & & $<0.001^{\mathrm{a}}$ \\
\hline Vascular invasion & & & 0.66 & Negative & 18 & 25 & \\
\hline Negative & 119 & 44 & & Positive & 153 & 41 & \\
\hline Positive & 47 & 20 & & E-cadherin & & & $0.009^{\mathrm{a}}$ \\
\hline Unknown & 5 & 2 & & Negative & 26 & 2 & \\
\hline Nuclear grade & & & $<0.001^{\mathrm{a}}$ & Positive & 145 & 64 & \\
\hline NG1 & 25 & 4 & & EpCAM & & & $<0.001^{\mathrm{a}}$ \\
\hline NG2 & 66 & 13 & & Negative & 122 & 31 & \\
\hline NG3 & 43 & 47 & & Positive & 48 & 35 & \\
\hline Unknown & 37 & 2 & & Unknown & 1 & 0 & \\
\hline ER & & & $<0.001^{\mathrm{a}}$ & Vimentin & & & $<0.001^{\mathrm{a}}$ \\
\hline Negative & 59 & 46 & & Negative & 153 & 35 & \\
\hline Positive & 112 & 20 & & Positive & 16 & 30 & \\
\hline $\operatorname{PgR}$ & & & $0.002^{\mathrm{a}}$ & Unknown & 2 & 1 & \\
\hline Negative & 89 & 49 & & $\overline{20}$ & . & . & +2 \\
\hline Positive & 82 & 17 & & $\begin{array}{l}{ }^{\mathrm{a}} \mathrm{P}<0.05 ;{ }^{\mathrm{b}} \mathrm{EGFR} \\
\text { subtype. ER, estrc }\end{array}$ & $\begin{array}{l}\text { tive or the } \mathrm{CK} \\
\text { receptor; } \mathrm{PgR}\end{array}$ & $\begin{array}{l}\text { positive in } t \\
\text { gesterone rec }\end{array}$ & $\begin{array}{l}\text { e-negative } \\
\text { or; HER2, }\end{array}$ \\
\hline HER2 & & & 0.692 & human epidermal $g$ & th factor recep & $2 ; \mathrm{IHC}, \mathrm{immu}$ & histochem- \\
\hline Score $0,1+$ & 136 & 54 & & istry; EGFR, epide & al growth fact & receptor; ALD & , aldehyde \\
\hline Score 2+, 3+ & 35 & 12 & & $\begin{array}{l}\text { dehydrogenase } 1 ; \\
\text { stathmin } 1 ; \text { EpCAM }\end{array}$ & $\begin{array}{l}\text { standard erro } \\
\text { pithelial cell ad }\end{array}$ & $\begin{array}{l}\mathrm{NG} \text {, nuclear gr } \\
\text { sion molecule. }\end{array}$ & STMN1, \\
\hline $\mathrm{Ki}-67$ labeling index $(\%)$, & $12.1 \pm 14.09$ & $40.6 \pm 29.01$ & $<0.001^{\mathrm{a}}$ & & & & \\
\hline
\end{tabular}

$\mathrm{Ki}-67$

$$
\text { Low }(\leq 14)
$$$$
\text { High (>14) }
$$

IHC based subtypes

Luminal A-like

Luminal B-like

Luminal-HER2

HER2

Triple-negative $<0.001^{\mathrm{a}}$

$<0.001^{\mathrm{a}}$

result was considered to be statistically significant when the relevant P-value was $<0.05$. All statistical analyses were performed with the IBM SPSS statistics, version 21.0 (IBM Corp., Armonk, NY, USA).

\section{Results}

Immunohistochemical analysis of STMN1 expression in breast cancer. We evaluated STMN1 expression using 

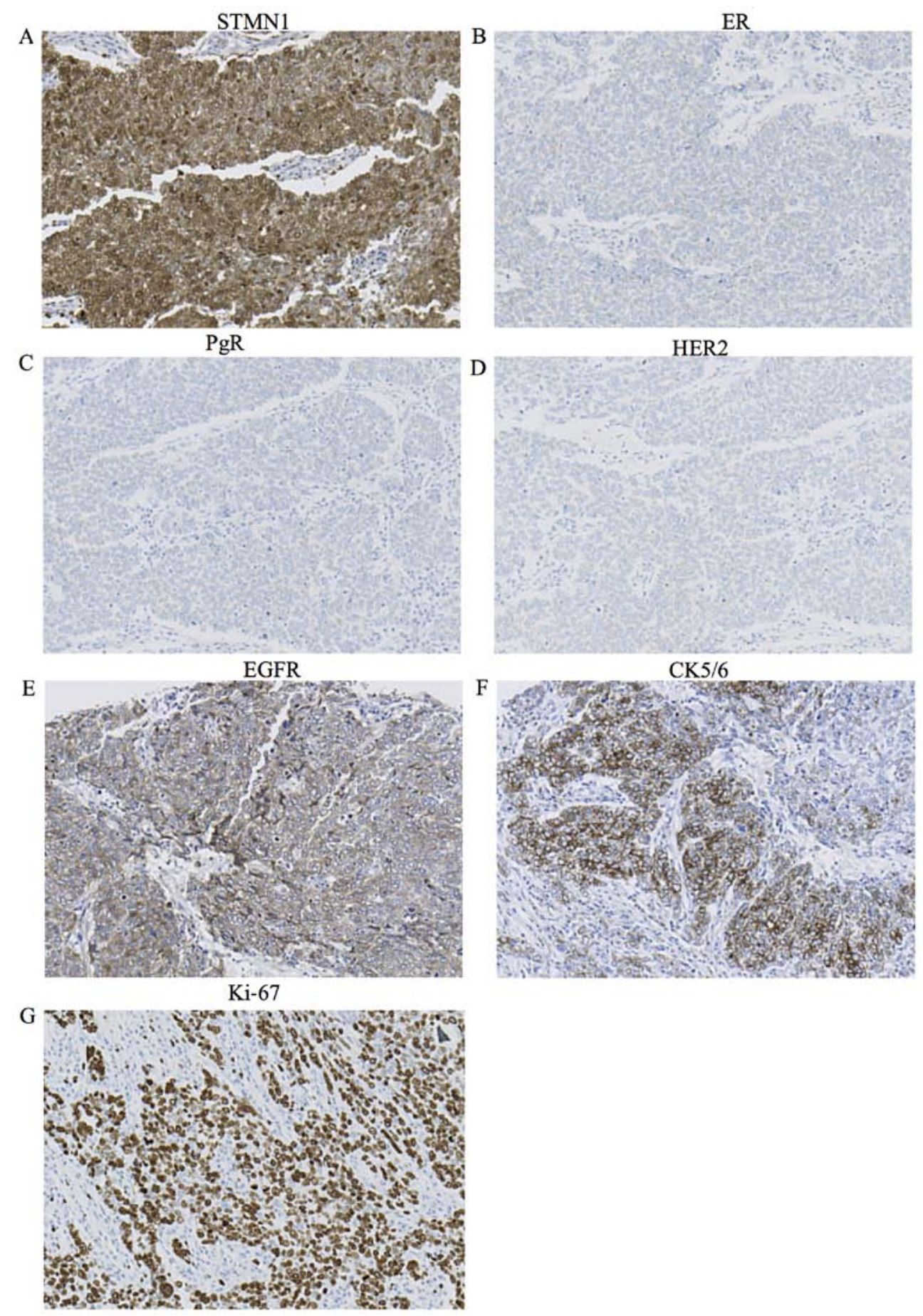

Figure 2. Immunohistochemical analysis of STMN1, ER, PgR, HER2, EGFR, CK5/6 and Ki-67 expression in the representative breast cancer tissue from a patient. (A) High STMN1 expression in the breast cancer tissue (magnification, x200). (B) Negative ER expression in the breast cancer tissue (magnification, x200). (C) Negative PgR expression in the breast cancer tissue (magnification, x200). (D) Negative HER2 expression in the breast cancer tissue (magnification, $\mathrm{x} 200$ ). (E) Positive EGFR expression in the breast cancer tissue (magnification, $\mathrm{x} 200$ ). (F) Positive CK5/6 expression in the breast cancer tissue (magnification, x200). (G) High Ki-67 expression in the breast cancer tissue (magnification, x200).

immunohistochemistry in 237 breast cancer TMA samples. Cytoplasmic expression of STMN1 in breast cancer tissue was higher than that in normal breast tissue (Fig. 1A and B). In total, $171(72.2 \%)$ breast cancer specimens were assigned to the low STMN1-expression group (Fig. 1C) and 66 (27.8\%) to the high STMN1-expression group (Fig. 1D).

Association between the expression of STMN1 and clinicopathological features of breast cancer. The correlations between STMN1 expression in breast cancer specimens and the clinicopathological characteristics of the patients are shown in Table I. Tumor nuclear grade was significantly higher in the STMN1-overexpression group $(\mathrm{P}<0.001)$. For the patients with tumor assigned to the high STMN1-expression group, there were significant associations with ER and $\mathrm{PgR}$ negativity $(\mathrm{P}<0.001, \mathrm{P}=0.002)$. According to IHC-based subtypes, the STMN1 expression level was significantly higher in the triple-negative subtype (Table I, P<0.001) (Fig. 2A-D). 
A

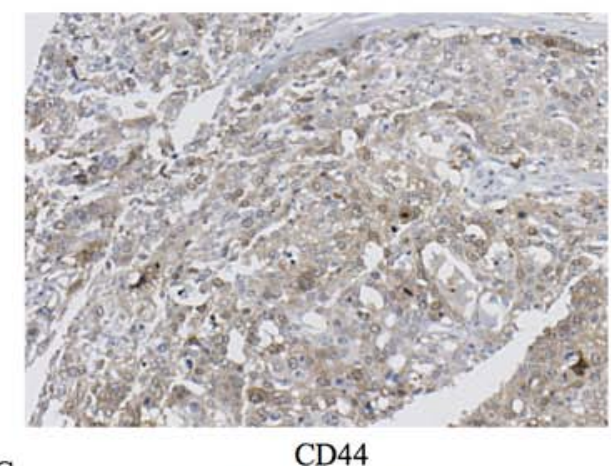

$\mathrm{C}$

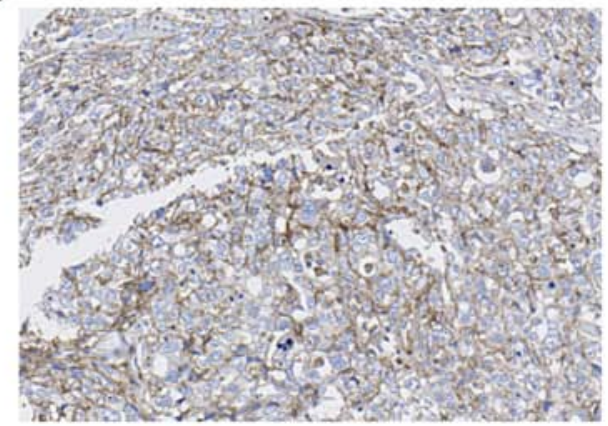

E

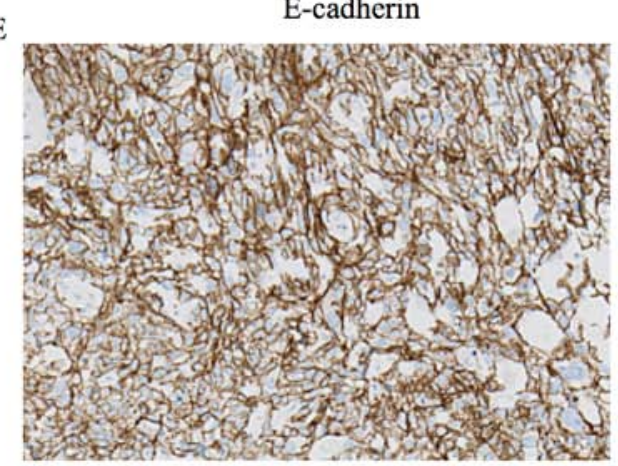

E-cadherin

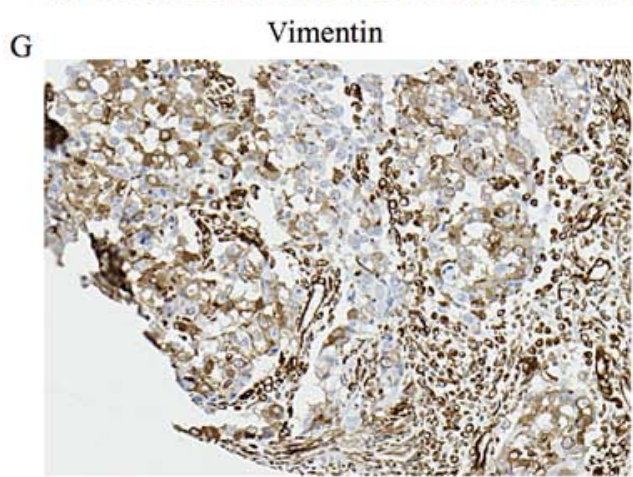

B

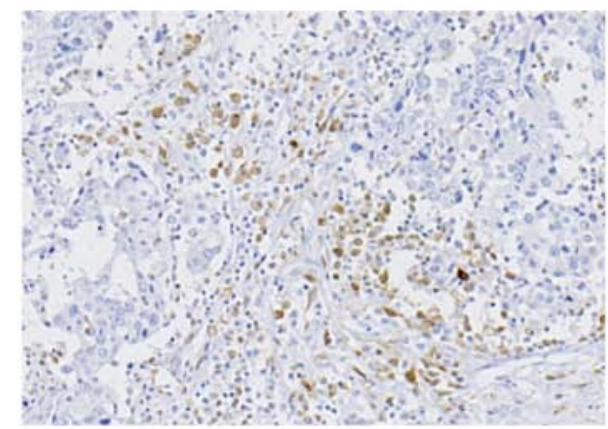

$\mathrm{D}$

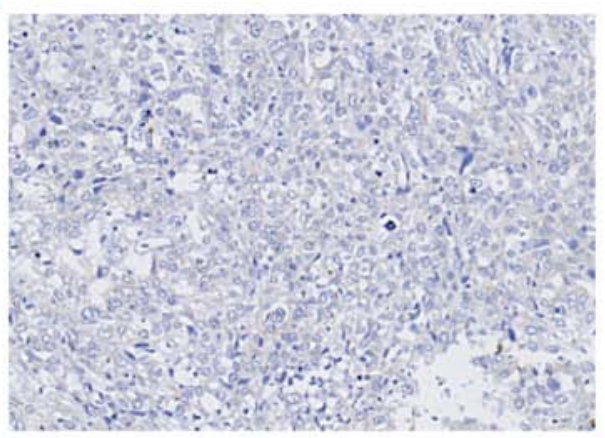

EpCAM

F

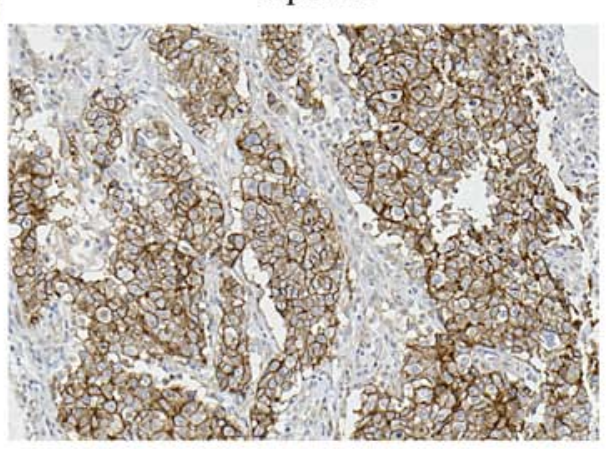

Figure 3. Immunohistochemical analysis of STMN1, ALDH1, CD44, CD24, E-cadherin, EpCAM and vimentin expression in a representative breast cancer tissue from a patient. (A) High STMN1 expression in the breast cancer tissue (magnification, x200). (B) High ALDH1 expression in the breast cancer tissue (magnification, x200). (C) High CD44 expression in the breast cancer tissue (magnification, x200). (D) Low CD24 expression in the breast cancer tissue (magnification, x200). (E) High E-cadherin expression in the breast cancer tissue (magnification, x200). (F) High EpCAM expression in the breast cancer tissue (magnification, x200). (G) High vimentin expression in the breast cancer tissue (magnification, x200).

Moreover, when EGFR positive or the CK5/6 positive in the triple-negative subtype were defined as basal-like subtype, the STMN1 expression level was also significantly higher in the basal-like subtype with EGFR or CK5/6 positivity (Table I, $\mathrm{P}<0.001$ ) (Fig. 2A, E and F). We also examined the association between STMN1 expression and Ki-67 LI. High STMN1-expressing patients showed significantly higher
Ki-67 LI than low STMN1-expressing patients (Table I, $\mathrm{P}<0.001$ ) (Fig. 2A and G). There were no correlations between STMN1 expression and patient age, tumor size, stage, lymph node metastasis, lymphatic invasion and vascular invasion.

We examined the association between STMN1 expression and immunohistochemical staining of existing BCSC markers ALDH1, CD44 and CD24. High STMN1 expression had a 


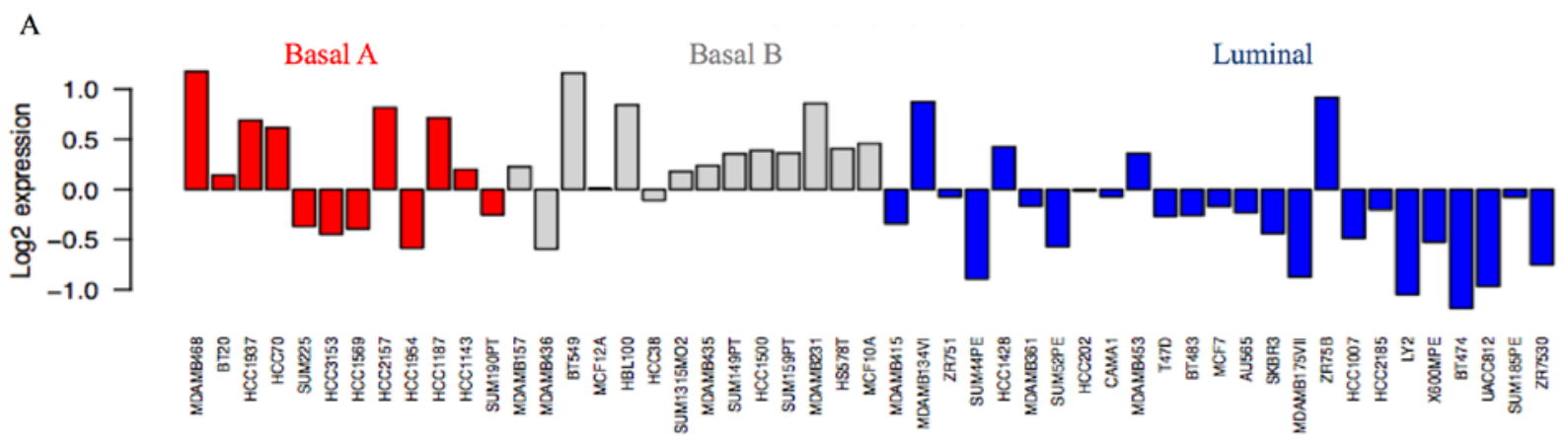

B

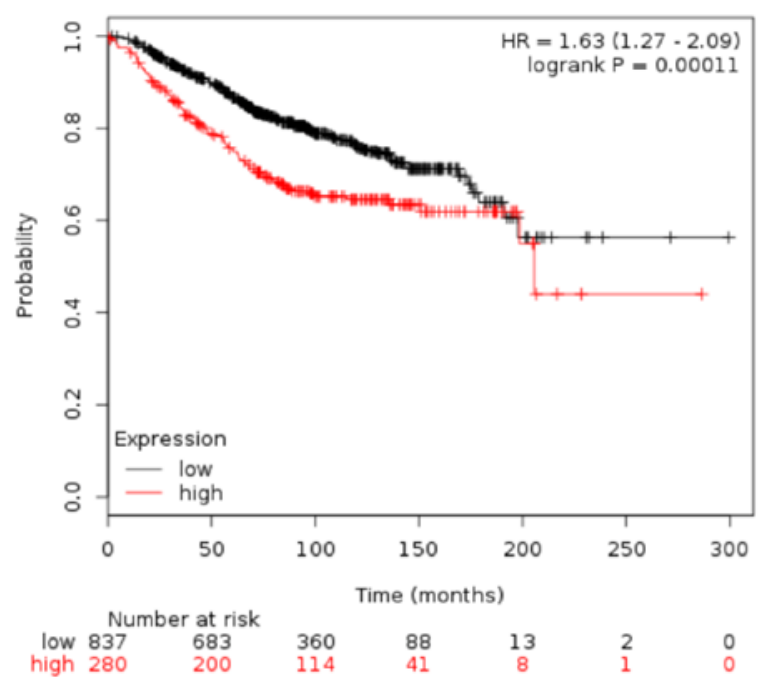

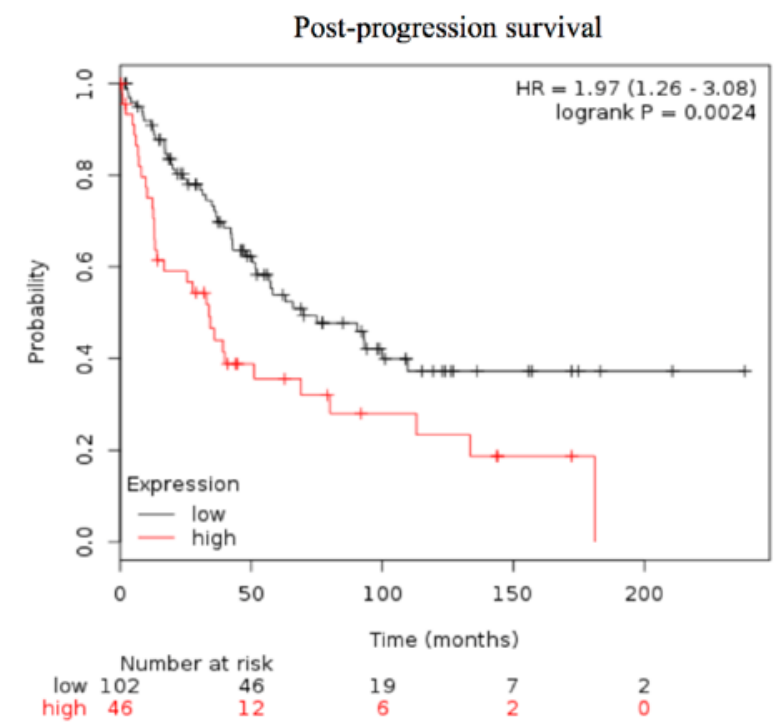

Figure 4. STMN1 expression in several breast cancer cell lines and prognostic significance of STMN1 in clinical breast cancer patients. (A) Gene expression of STMN1 in different breast cancer cell lines; adapted from GOBO: http://co.bmc.lu.se/gobo/gsa_cellines.pl. (B) Kaplan-Meier survival curves of breast cancer patients expressing high or low STMN1; adapted from KM plotter: http://kmplot.com. Left and right panels show the overall survival curve and the post-progression survival curve, respectively.

strong association with high CD44/low CD24 expression and a tendency with high ALDH1 expression related to the BCSC phenotypes (Table I, P<0.001, P<0.001) (Fig. 3A-D). We also examined the association between the expression on STMN1 and that of epithelial markers such as E-cadherin and EpCAM. High STMN1 expression was associated with high E-cadherin expression and high EpCAM expression (Table I, $\mathrm{P}=0.009, \mathrm{P}<0.001$ ) (Fig. 3A, E and F). Furthermore, we examined the association between STMN1 expression and vimentin expression. High STMN1 expression was associated with high vimentin expression (Table I, $\mathrm{P}<0.001)$ (Fig. 3A and G).

We investigated STMN1 mRNA expression levels in the 51 breast cancer cell lines using the public breast cancer database GOBO. STMN1 mRNA expression was higher in the basal A and basal B subgroups than in the luminal subgroups (Fig. 4A).

Association between the expression of STMN1 and clinicopathological features of TNBCs. The correlations between the expression of STMN1 in TNBC specimens and the clinicopathological features of the patients are shown in Table II. Tumor nuclear grade and Ki-67 LI were significantly higher in the STMN1-overexpression group in the TNBC subtype (Table II, $\mathrm{P}=0.007, \mathrm{P}<0.001)$. Furthermore, high STMN1 expression had a strong association with high CD44 /low CD24 expression in the TNBC subtype (Table II, $\mathrm{P}=0.035, \mathrm{P}=0.035$ ).

Prognostic significance of STMN1 expression in breast cancer patients. In our breast cancer cohort, RFS and OS in relation to STMN1 expression were not significant (data not shown). However, the survival time in breast cancer patients with high STMN1 expression was slightly worse than those with low STMN1 expression. The median follow-up period of OS was 110 months.

To examine the prognostic significance of STMN1 in a large cohort of breast cancer patients, we examined the correlation between STMN1 mRNA expression and prognosis using the public database KM plotter. High STMN1 mRNA expression correlated with poor OS in 1117 breast cancer patients [Fig. 4B, left panel, hazard ratio (HR), 1.63, 95\% confidence interval (CI), 1.27-2.09; $\mathrm{P}<0.001]$ and poor post-progression survival in 148 breast cancer patients (Fig. 4B, right panel; HR, 1.97, 95\% CI, 1.26-3.08; $\mathrm{P}=0.0024)$.

\section{Discussion}

In the present study, we determined that high levels of STMN1 expression are associated with nuclear grade progression, 
Table II. Correlation between the expression of STMN1 and the clinicopathological characteristics of TNBCs.

\begin{tabular}{|c|c|c|}
\hline \multirow[b]{2}{*}{ Characteristics } & \multicolumn{2}{|c|}{ STMN1 expressi } \\
\hline & $\begin{array}{c}\text { Low } \\
\text { expression } \\
(n=30)\end{array}$ & $\begin{array}{r}\mathrm{H} \\
\text { expre } \\
(\mathrm{n}=\end{array}$ \\
\hline $\begin{array}{l}\text { Age (years), } \\
\text { mean } \pm \mathrm{SE}\end{array}$ & $61.4 \pm 10.89$ & $55.5 \pm$ \\
\hline $\begin{array}{l}\text { Tumor size }(\mathrm{cm}), \\
\text { mean } \pm \mathrm{SE}\end{array}$ & $2.3 \pm 1.12$ & $2.7 \pm$ \\
\hline \multicolumn{3}{|l|}{ Stage } \\
\hline 0 & 0 & \\
\hline I & 11 & 1 \\
\hline II & 10 & 1 \\
\hline III & 9 & \\
\hline \multicolumn{3}{|c|}{ Lymph node metastasis } \\
\hline Negative & 19 & 1 \\
\hline Positive & 11 & 1 \\
\hline Unknown & 0 & \\
\hline \multicolumn{3}{|c|}{ Lymphatic invasion } \\
\hline Negative & 12 & 1 \\
\hline Positive & 18 & 2 \\
\hline \multicolumn{3}{|l|}{ Vascular invasion } \\
\hline Negative & 20 & 1 \\
\hline Positive & 9 & 1 \\
\hline Unknown & 1 & \\
\hline \multicolumn{3}{|l|}{ Nuclear grade } \\
\hline NG1 & 4 & \\
\hline NG2 & 5 & \\
\hline NG3 & 15 & 3 \\
\hline Unknown & 6 & \\
\hline
\end{tabular}

Ki-67 labeling index (\%), $19.4 \pm 23.79 \quad 55.0 \pm 27.20<0.001^{\mathrm{a}}$ mean $\pm \mathrm{SE}$

Ki-67

Low $(\leq 14)$

17

High $(>14)$

EGFR

Negative

Positive

CK5/6

Negative

Positive

Basal-like type

Basal

Non-basal

ALDH1

Negative

Positive

CD44

Negative

Positive $0.007^{\mathrm{a}}$

2

32

1
Table II. Continued.

\begin{tabular}{lccc}
\hline & \multicolumn{2}{c}{ STMN1 expression } & \\
\cline { 2 - 3 } & $\begin{array}{c}\text { Low } \\
\text { expression } \\
(\mathrm{n}=30)\end{array}$ & $\begin{array}{c}\text { High } \\
\text { expression } \\
(\mathrm{n}=35)\end{array}$ & P-value \\
\hline Characteristics & & & $0.035^{\mathrm{a}}$ \\
Negative & 11 & 22 & \\
Positive & 19 & 13 & 0.087 \\
E-cadherin & & 1 & \\
Negative & 5 & 34 & 0.077 \\
Positive & 25 & 10 & \\
EpCAM & & 25 & $0.001^{\mathrm{a}}$ \\
Negative & 15 & & \\
Positive & 15 & 10 & \\
Vimentin & & 25 & \\
Negative & 21 & & \\
Positive & 9 & & \\
\hline
\end{tabular}

${ }^{\mathrm{a}} \mathrm{P}<0.05$. ${ }^{\mathrm{b}} \mathrm{EGFR}$ positive or the $\mathrm{CK} 5 / 6$ positive in triple-negative subtype. EGFR, epidermal growth factor receptor; ALDH1, aldehyde dehydrogenase 1; SE, standard error; NG, nuclear grade; STMN1, stathmin1; EpCAM, epithelial cell adhesion molecule.

TNBC phenotype and Ki-67 expression in patients with breast cancer. Moreover, we demonstrated that STMN1 expression was related to CSC-marker expression, such as high CD44/low CD24 expression and ALDH1.

STMN1 favors microtubule depolymerization by binding to tubulin heterodimers (5). Taxanes are microtubule-stabilizing agents commonly used in chemotherapy for treating breast cancer (32). STMN1 overexpression decreases microtubule polymerization and the breast cancer cell bond for paclitaxel weakens, leading to therapeutic resistance (23). The effect of preoperative chemotherapy containing docetaxel was low in the STMN1-overexpression group (33). In the present study, using the KM plotter, it was suggested that post-progression survival was significantly worse and the response to treatment 0.964 after recurrence was lower in the STMN1-overexpression group. Furthermore, silencing STMN1 induces microtubule polymerization and sensitizes STMN1-overexpressing breast cancer cells to antimicrotubule agents (34). Taxol and antiSTMN1 therapy have a synergistic anticancer effect on a leukemic cell line (35). In the future, therapeutic resistance to taxanes may be overcome by developing STMN1-targeted treatments.

CSCs are a small cell population with unique characteristics, such as self-renewal and multipotency, and show aggressive phenotypes and therapeutic resistance by various mechanisms (e.g., ABC transporter, ALDH activity, DNA repair and reactive oxygen species scavenging) $(36,37)$. Therefore, CSCs are resistant to many cancer treatments and cause new recurrence and metastasis by their aggressive phenotypes. Therefore, as CSCs are closely associated with cancer progression and metastasis, CSC-targeted therapy 
development may exterminate a cancer. EMT also has an important role in cancer progression and metastasis. Through EMT, cancer cells lose cell adhesion, gain invasive ability and cause vascular invasion and metastases $(18,19)$. Although some studies have indicated a close association between CSCs and EMT state acquisition (38), others have suggested that EMT and CSC states are independent $(39,40)$. EMT induction in human mammary epithelial cells by transcription factor expression, such as TGF- $\beta$ or snail, results in mesenchymal trait acquisition and stem-cell marker expression (38). In contrast, Biddle et al (39) and Liu et al (40) suggested the presence of EMT CSCs and non-EMT CSCs. Non-EMT CSCs, similar to normal epithelial stem cells, have the ability of self-renewal and cell proliferation. EMT CSCs can migrate and are characterized by transient expression of EMT-associated genes, which can be reversed by MET, and therefore, enable secondary tumor formation at a metastatic site. Non-EMT CSCs and EMT CSCs can switch their epithelial or mesenchymal traits to reconstitute the cellular heterogeneity, which is characteristic of CSCs. There are a few reports that have described an association between STMN1, CSCs and EMT. Sival suppresses EMT and metastasis of tumor cells by inhibiting STMN1 and stabilizing microtubules and an association was suggested between STMN1 and EMT CSC (41). In this study, we demonstrated that high STMN1 expression had a strong association with high CD44/ low CD24 expression and suggested an association between STMN1 expression and CSCs. We also demonstrated that the expression of STMN1 expression correlated with that of E-cadherin and EpCAM, which are epithelial markers, and vimentin, which is a mesenchymal marker. In other words, it was difficult to distinguish EMT CSCs and non-EMT CSCs by STMN1 expression in this study. However, these two states can switch their epithelial or mesenchymal traits, and the presence of cells that co-express epithelial and mesenchymal markers has been suggested (42). Furthermore, a study by Abell et al (43) showed that CSCs may represent a population of cells in an intermediate state of EMT. These cells express low-to-moderate levels of E-cadherin, and simultaneously, they exhibit mesenchymal features. STMN1 may be a marker detecting such an intermediated phenotype harboring both of EMT and non-EMT.

Because there is no indication for TNBCs in endocrine therapy or HER2 inhibitors, novel molecular-targeted therapies against TNBCs are crucially needed. TNBCs have loss of PTEN more frequently, and the PI3K pathway is strongly activated in these tumors (44-46). PTEN loss correlates with STMN1 expression, and STMN1 expression becomes a good marker of the PI3K pathway activation (20). In this study, the STMN1 expression level was significantly higher in the TNBCs. Assessment of STMN1 expression may be a clinically useful test for the stratification of patients for anti-PI3K pathway therapy and for monitoring therapeutic efficacy.

As described above, it is hoped that STMN1 becomes a good therapeutic target in refractory breast cancer and recurrent breast cancer. However, there are several limitations to this study. First, due to the small number of patients, there was not a significant difference between STMN1 expression and prognosis. Second, there were many older patients in whom the treatment regimen differed from present regimens. Therefore, in the future, large cohort prospective validation studies are needed. However, for TNBCs with STMN1 overexpression in this study, preoperative chemotherapy is often currently recommended. Therefore, the evaluation of needle biopsy tissues is required to assess STMN1 expression in treatment-free tissue. Because STMN1 expression has relatively little heterogeneity in the tissues, we were able to show a significant association between STMN1 expression and CSCs by evaluating TMAs. It is expected that large cohort prospective studies using needle biopsy tissues before treatment will be conducted in the future to examine the significance of STMN1 as a predictive marker for therapeutic effect and as a prognostic marker.

In conclusion, we found that high STMN1 expression could be a powerful marker of cancer cell proliferation, TNBC phenotypes and cancer stem cells in breast cancer patients.

\section{Acknowledgements}

The present study was supported by Grants-in-Aid for Scientific Research from the Japan Society for the Promotion of Science (grant no. 26461939). This study was also supported in part by Uehara Zaidan; the Medical Research Encouragement Prize of The Japan Medical Association; the Promotion Plan for the Platform of Human Resource Development for Cancer and New Paradigms-Establishing Centers for Fostering Medical Researchers of the Future programs by the Ministry of Education, Culture, Sports, Science and Technology of Japan; and the Gunma University Initiative for Advanced Research.

\section{References}

1. Torre LA, Bray F, Siegel RL, Ferlay J, Lortet-Tieulent J and Jemal A: Global cancer statistics, 2012. CA Cancer J Clin 65: 87-108, 2015

2. Belmont LD and Mitchison TJ: Identification of a protein that interacts with tubulin dimers and increases the catastrophe rate of microtubules. Cell 84: 623-631, 1996.

3. Curmi PA, Gavet O, Charbaut E, Ozon S, Lachkar-Colmerauer S, Manceau V, Siavoshian S, Maucuer A and Sobel A: Stathmin and its phosphoprotein family: General properties, biochemical and functional interaction with tubulin. Cell Struct Funct 24: 345-357, 1999.

4. Cassimeris L: The oncoprotein 18/stathmin family of microtubule destabilizers. Curr Opin Cell Biol 14: 18-24, 2002.

5. Curmi PA, Andersen SS, Lachkar S, Gavet O, Karsenti E, Knossow $M$ and Sobel A: The stathmin/tubulin interaction in vitro. J Biol Chem 272: 25029-25036, 1997.

6. Curmi PA, Noguès C, Lachkar S, Carelle N, Gonthier MP, Sobel A, Lidereau R and Bièche I: Overexpression of stathmin in breast carcinomas points out to highly proliferative tumours. $\mathrm{Br}$ J Cancer 82: 142-150, 2000.

7. Arnedos M, Drury S, Afentakis M, A'Hern R, Hills M, Salter J Smith IE, Reis-Filho JS and Dowsett M: Biomarker changes associated with the development of resistance to aromatase inhibitors (AIs) in estrogen receptor-positive breast cancer. Ann Oncol 25: 605-610, 2014.

8. Perou CM, Sørlie T, Eisen MB, van de Rijn M, Jeffrey SS Rees CA, Pollack JR, Ross DT, Johnsen H, Akslen LA, et al: Molecular portraits of human breast tumours. Nature 406: 747-752, 2000.

9. Sørlie T, Perou CM, Tibshirani R, Aas T, Geisler S, Johnsen H, Hastie T, Eisen MB, van de Rijn M, Jeffrey SS, et al: Gene expression patterns of breast carcinomas distinguish tumor subclasses with clinical implications. Proc Natl Acad Sci USA 98: 10869-10874, 2001.

10. Goldhirsch A, Winer EP, Coates AS, Gelber RD, Piccart-Gebhart M, Thürlimann B, Senn HJ, Albain KS, André F, Bergh J, et al; Panel members: Personalizing the treatment of women with early breast cancer: Highlights of the St Gallen International Expert Consensus on the Primary Therapy of Early Breast Cancer 2013. Ann Oncol 24: 2206-2223, 2013. 
11. Dent R, Trudeau M, Pritchard KI, Hanna WM, Kahn HK, Sawka CA, Lickley LA, Rawlinson E, Sun P and Narod SA: Triple-negative breast cancer: clinical features and patterns of recurrence. Clin Cancer Res 13: 4429-4434, 2007.

12. Giatromanolaki A, Sivridis E, Fiska A and Koukourakis MI: The CD $44^{+} / \mathrm{CD} 24$ - phenotype relates to 'triple-negative' state and unfavorable prognosis in breast cancer patients. Med Oncol 28: 745-752, 2011.

13. Idowu MO, Kmieciak M, Dumur C, Burton RS, Grimes MM, Powers $\mathrm{CN}$ and Manjili $\mathrm{MH}$ : CD $44^{+} / \mathrm{CD} 24^{-/ \text {low }}$ cancer stem/ progenitor cells are more abundant in triple-negative invasive breast carcinoma phenotype and are associated with poor outcome. Hum Pathol 43: 364-373, 2012.

14. Al-Hajj M, Wicha MS, Benito-Hernandez A, Morrison SJ and Clarke MF: Prospective identification of tumorigenic breast cancer cells. Proc Natl Acad Sci USA 100: 3983-3988, 2003.

15. Ginestier C, Hur MH, Charafe-Jauffret E, Monville F, Dutcher J, Brown M, Jacquemier J, Viens P, Kleer CG, Liu S, et al: ALDH1 is a marker of normal and malignant human mammary stem cells and a predictor of poor clinical outcome. Cell Stem Cell 1: 555-567, 2007.

16. Shafee N, Smith CR, Wei S, Kim Y, Mills GB, Hortobagyi GN, Stanbridge EJ and Lee EY: Cancer stem cells contribute to cisplatin resistance in Brca1/p53-mediated mouse mammary tumors. Cancer Res 68: 3243-3250, 2008

17. To K, Fotovati A, Reipas KM, Law JH, Hu K, Wang J, Astanehe A, Davies AH, Lee L, Stratford AL, et al: Y-box binding protein-1 induces the expression of CD44 and CD49f leading to enhanced self-renewal, mammosphere growth, and drug resistance. Cancer Res 70: 2840-2851, 2010.

18. Thiery JP: Epithelial-mesenchymal transitions in tumour progression. Nat Rev Cancer 2: 442-454, 2002

19. Guarino M, Rubino B and Ballabio G: The role of epithelialmesenchymal transition in cancer pathology. Pathology 39: 305-318, 2007.

20. Saal LH, Johansson P, Holm K, Gruvberger-Saal SK, She QB, Maurer M, Koujak S, Ferrando AA, Malmström P, Memeo L, et al: Poor prognosis in carcinoma is associated with a gene expression signature of aberrant PTEN tumor suppressor pathway activity. Proc Natl Acad Sci USA 104: 7564-7569, 2007.

21. Golouh R, Cufer T, Sadikov A, Nussdorfer P, Usher PA, Brünner N, Schmitt M, Lesche R, Maier S, Timmermans M, et al: The prognostic value of Stathmin-1, S100A2, and SYK proteins in ER-positive primary breast cancer patients treated with adjuvant tamoxifen monotherapy: An immunohistochemical study. Breast Cancer Res Treat 110: 317-326, 2008.

22. Baquero MT, Hanna JA, Neumeister V, Cheng H, Molinaro AM, Harris LN and Rimm DL: Stathmin expression and its relationship to microtubule-associated protein tau and outcome in breast cancer. Cancer 118: 4660-4669, 2012.

23. Alli E, Bash-Babula J, Yang JM and Hait WN: Effect of stathmin on the sensitivity to antimicrotubule drugs in human breast cancer. Cancer Res 62: 6864-6869, 2002.

24. Sobin LH, Gospodarowicz MK and Wittekind C: TNM Classification of Malignant Tumours. 7th edition. WileyBlackwell, 2009.

25. Tsuda H, Akiyama F, Kurosumi M, Sakamoto G and Watanabe T; Japan National Surgical Adjuvant Study of Breast Cancer (NSAS-BC) Pathology Section: Establishment of histological criteria for high-risk node-negative breast carcinoma for a multiinstitutional randomized clinical trial of adjuvant therapy. Jpn J Clin Oncol 28: 486-491, 1998.

26. Wolff AC, Hammond ME, Hicks DG, Dowsett M, McShane LM, Allison KH, Allred DC, Bartlett JM, Bilous M, Fitzgibbons P, et al; American Society of Clinical Oncology; College of American Pathologists: Recommendations for human epidermal growth factor receptor 2 testing in breast cancer: American Society of Clinical Oncology/College of American Pathologists clinical practice guideline update. J Clin Oncol 31: 3997-4013, 2013.

27. Dowsett M, Nielsen TO, A'Hern R, Bartlett J, Coombes RC, Cuzick J,Ellis M, Henry NL, Hugh JC, Lively T, et al; International $\mathrm{Ki}-67$ in Breast Cancer Working Group: Assessment of Ki-67 in breast cancer: Recommendations from the International Ki-67 in Breast Cancer working group. J Natl Cancer Inst 103: 1656-1664, 2011.
28. Cheang MC, Chia SK, Voduc D, Gao D, Leung S, Snider J, Watson M, Davies S, Bernard PS, Parker JS, et al: Ki67 index, HER2 status, and prognosis of patients with luminal B breast cancer. J Natl Cancer Inst 101: 736-750, 2009.

29. Allred DC, Harvey JM, Berardo M and Clark GM: Prognostic and predictive factors in breast cancer by immunohistochemical analysis. Mod Pathol 11: 155-168, 1998.

30. Ringnér M, Fredlund E, Häkkinen J, Borg Å and Staaf J: GOBO: Gene expression-based outcome for breast cancer online. PLoS One 6: e17911, 2011.

31. Györffy B, Lanczky A, Eklund AC, Denkert C, Budczies J, Li Q and Szallasi Z: An online survival analysis tool to rapidly assess the effect of 22,277 genes on breast cancer prognosis using microarray data of 1,809 patients. Breast Cancer Res Treat 123: 725-731, 2010.

32. McGrogan BT, Gilmartin B, Carney DN and McCann A: Taxanes, microtubules and chemoresistant breast cancer. Biochim Biophys Acta 1785: 96-132, 2008.

33. Meng XL, Su D, Wang L, Gao Y, Hu YJ, Yang HJ and Xie SN: Low expression of stathmin in tumor predicts high response to neoadjuvant chemotherapy with docetaxel-containing regimens in locally advanced breast cancer. Genet Test Mol Biomarkers 16: 689-694, 2012

34. Alli E, Yang JM, Ford JM and Hait WN: Reversal of stathminmediated resistance to paclitaxel and vinblastine in human breast carcinoma cells. Mol Pharmacol 71: 1233-1240, 2007.

35. Iancu C, Mistry SJ, Arkin S and Atweh GF: Taxol and antistathmin therapy: A synergistic combination that targets the mitotic spindle. Cancer Res 60: 3537-3541, 2000.

36. Dean M, Fojo T and Bates S: Tumour stem cells and drug resistance. Nat Rev Cancer 5: 275-284, 2005.

37. Zhao J: Cancer stem cells and chemoresistance: The smartest survives the raid. Pharmacol Ther 160: 145-158, 2016.

38. Mani SA, Guo W, Liao MJ, Eaton EN, Ayyanan A, Zhou AY, Brooks M, Reinhard F, Zhang CC, Shipitsin M, et al: The epithelial-mesenchymal transition generates cells with properties of stem cells. Cell 133: 704-715, 2008.

39. Biddle A, Liang X, Gammon L, Fazil B, Harper LJ, Emich H, Costea DE and Mackenzie IC: Cancer stem cells in squamous cell carcinoma switch between two distinct phenotypes that are preferentially migratory or proliferative. Cancer Res 71: 5317-5326, 2011.

40. Liu S, Cong Y, Wang D, Sun Y, Deng L, Liu Y, Martin-Trevino R, Shang L, McDermott SP, Landis MD, et al: Breast cancer stem cells transition between epithelial and mesenchymal states reflective of their normal counterparts. Stem Cell Rep 2: 78-91, 2013.

41. Li N, Jiang P, Du W, Wu Z, Li C, Qiao M, Yang X and Wu M: Siva1 suppresses epithelial-mesenchymal transition and metastasis of tumor cells by inhibiting stathmin and stabilizing microtubules. Proc Natl Acad Sci USA 108: 12851-12856, 2011.

42. Yu M, Bardia A, Wittner BS, Stott SL, Smas ME, Ting DT, Isakoff SJ, Ciciliano JC, Wells MN, Shah AM, et al: Circulating breast tumor cells exhibit dynamic changes in epithelial and mesenchymal composition. Science 339: 580-584, 2013.

43. Abell AN and Johnson GL: Implications of mesenchymal cells in cancer stem cell populations: Relevance to EMT. Curr Pathobiol Rep 2: 21-26, 2014

44. Depowski PL, Rosenthal SI and Ross JS: Loss of expression of the PTEN gene protein product is associated with poor outcome in breast cancer. Mod Pathol 14: 672-676, 2001.

45. Saal LH, Holm K, Maurer M, Memeo L, Su T, Wang X, Yu JS, Malmström PO, Mansukhani M, Enoksson J, et al: PIK3CA mutations correlate with hormone receptors, node metastasis, and ERBB2, and are mutually exclusive with PTEN loss in human breast carcinoma. Cancer Res 65: 2554-2559, 2005.

46. Perren A, Weng LP, Boag AH, Ziebold U, Thakore K, Dahia PL, Komminoth P, Lees JA, Mulligan LM, Mutter GL, et al: Immunohistochemical evidence of loss of PTEN expression in primary ductal adenocarcinomas of the breast. Am J Pathol 155: 1253-1260, 1999. 